\title{
Diarrhea in Breastfed versus Formulafed Baby: A Hospital Based Study in 150 Children
}

\author{
MUH BEGUM $^{\mathrm{a}}$, MNABSAR ${ }^{\mathrm{b}}$
}

\begin{abstract}
Summary:
Background: Breastfeeding reduces incidence of common childhood illnesses such as diarrhea and thus reduces infant mortality and morbidity.
\end{abstract}

Objective: To find out the incidence of diarrhea in breastfed versus formula fed baby.

Methodology: An observational cross sectional study was carried out in the Pediatric department of Northern private medical college hospital, Rangpur from March 2013 to June 2014. Total 150 children aged 1 to 24 months having diarrhea were enrolled in the study.

Result: Mean age of children was 11.6 with $S D \pm 5.29$ months, ranges from 1 month to 23 months in which exclusively breast fed $51.3 \%$, breast fed plus formula fed $39.3 \%$, exclusively formula fed $9.4 \%$; single attack of diarrhea occurred in $72.7 \%, 40.7 \%$, and $28.6 \%$ children in exclusively breast fed, breast fed plus formula fed and exclusively formula fed children respectively. Frequent attack of diarrhea occurred in $27.3 \%, 59.3 \%$ and $71.4 \%$ children

\section{Introduction:}

Breastfeeding is an unequalled way of providing ideal food for the healthy growth and development of infants ${ }^{1}$. Breast milk promotes sensory and cognitive development, and protects the infant against infectious and chronic diseases. Exclusive breastfeeding reduces infant mortality due to common childhood illnesses such as diarrhea, and helps for a quicker recovery during illness ${ }^{2}$. Breast milk contains all nutrients as well as antibodies especially Immunoglobulin A (IgA) and protects baby from infections including diarrheal diseases. WHO has recommended, infants should be

a. Dr. Most. Umme Habiba Begum, Assistant Professor, Dept. of Pediatrics, Northern Private Medical College, Rangpur.

b. Prof. MN Absar, Professor \& Head, Dept. of Pediatrics, Northern Private Medical College, Rangpur.

Address of Correspondence: Dr. Most. Umme Habiba Begum, Assistant Professor, Dept. of Pediatrics, Northern Private Medical College, Rangpur. Mobile: 01769662956, 01191295626, E-mail: arafanis@gmail.com

Received: 19 October, 2014

Accepted: 1 March, 2015 in exclusively breast fed, breast fed plus formula fed and exclusively formula fed children respectively; among 59 patients who developed first attack of diarrhea by 6 months of age, $10.2 \%, 69.5 \%$ and $20.3 \%$ were from exclusively breast fed, breast fed plus formula fed and exclusively formula fed children respectively. Patients who developed first attack of diarrhea by 7-12 months of age, 69.8\% were from exclusively breast fed, $27.0 \%$ from breast fed plus formula fed and 3.2\% from exclusively formula fed children. But 28 children whose first diarrhea occurred by 13-24 months of age, $96.4 \%$ and $3.6 \%$ were from exclusively breast fed, and breast fed plus formula fed group respectively.

Conclusion: Breast feeding reduces incidence of diarrhea, prevents frequent attack and early occurrence of diarrhea in under two children.

Key words: Exclusive breastfeeding, Formula feeding, Diarrhea.

(J Banagladesh Coll Phys Surg 2016; 34: 21-25)

exclusively breastfed for the first six months of life to achieve optimal growth, development and health. Breast milk substitutes (such as commercial infant formulas and cow's milk) are considered nutritionally acceptable for few infants, but there is greater risk of developing a number of infections including diarrhea. Breast milk substitutes and other baby foods as well as bottles, teats and utensil are attributable to contamination causing diarrheal diseases in infants who are not exclusively breastfed.

Objectives of the Study

To find out the incidence of diarrhea in breastfed versus formula fed baby.

Methodology:

This observational cross sectional study was carried out in the Pediatric department of Northern Private Medical College Hospital, Rangpur from March 2013 to June 2014. Total 150 children aged 1 to 24 months were included in the study. Children having diarrhea attending in and out patient department were enrolled in this study. Data were collected by face to face interview using a 
structured close ended questionaire information regarding demographic data; containing detailed feeding history and information of diarrhea. All the parents and attendants were informed about the purpose of the study and verbal consent was obtained. Children aged less than 1 month or more than 24 months and the children whose mother were not agreed to include in the study were excluded. Data were processed by using SPSS-19 program. Frequency distributions and proportions were calculated for the values. Students unpaired $t$ test were applied as statistical tools. P value of $<0.05$ was considered as significance. There was no ethical problem, as because verbal consent of parents and attendants were taken before conducting interview for the study.

\section{Results:}

Age of the study population ranges from 1 month to 23 months. Mean age was 11.6 with SD; \pm 5.29 months. Demography of the study population is as follows:

Figure 1 shows, single attack of diarrhea occurred in 56 (72.7\%), 24 (40.7\%), and 4 (28.6\%) children in exclusively breast fed, breast fed plus formula fed and exclusively

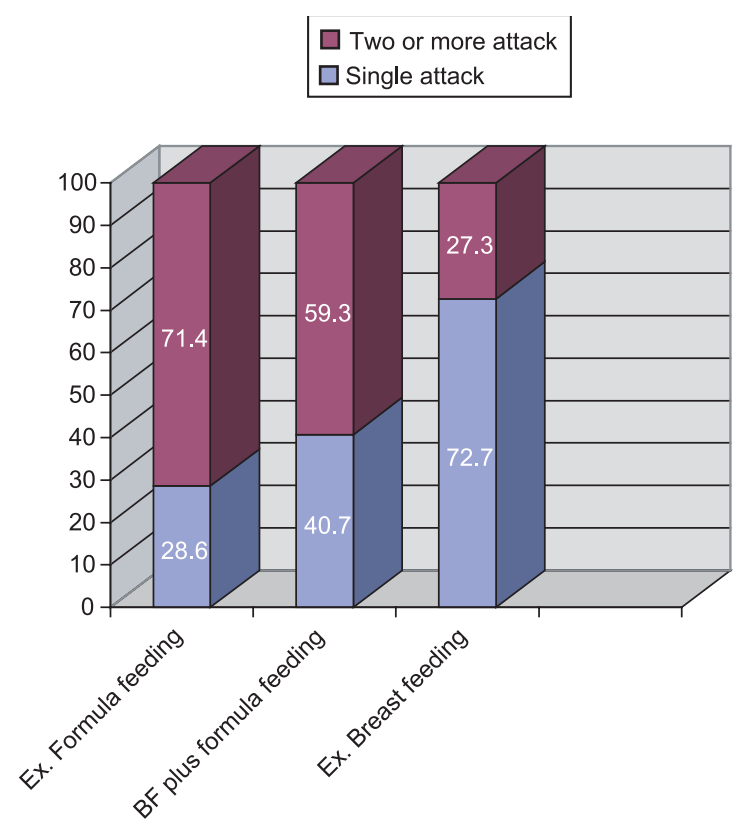

Fig.-1: Relationship between feeding and number of diarrheal attack

formula fed group respectively. Frequent $(\geq 2)$ attack of diarrhea occurred in 21(27.3\%), 35 (59.3\%) and 10 (71.4\%) children in exclusively breast fed, breast fed plus formula fed and exclusively formula fed group respectively ( $\mathrm{p}$ value .000).

\section{Table-I}

\begin{tabular}{|c|c|c|c|}
\hline \multicolumn{4}{|c|}{ Demography of study population } \\
\hline Parameters & No. (\%) & Parameters & No. (\%) \\
\hline Age group & \multicolumn{3}{|c|}{ Sanitation } \\
\hline 1 to 6 month & $30(20.0)$ & Pacca & $94(62.7)$ \\
\hline 7 to12 month & $60(40.0)$ & Water seal & $15(10.0)$ \\
\hline 13 to18 month & 47 (31.3) & Kacha & 38 (25.3) \\
\hline 19 to24 month & $13(08.7)$ & Open air & $03(02.0)$ \\
\hline Sex & \multicolumn{3}{|c|}{ Residence } \\
\hline Male & $102(68.0)$ & Urban & 65 (43.3) \\
\hline \multirow[t]{2}{*}{ Female } & \multirow{2}{*}{$48(32.0)$} & Rural & $79(52.7)$ \\
\hline & & Urban slum & $06(04.0)$ \\
\hline \multicolumn{2}{|l|}{ Fathers' education } & \multicolumn{2}{|l|}{$\begin{array}{l}\text { Mothers' } \\
\text { education }\end{array}$} \\
\hline Illiterate & $22(14.7)$ & Illiterate & $22(14.7)$ \\
\hline Primary & $33(22.0)$ & Primary & $54(36.0)$ \\
\hline Secondary & $49(32.7)$ & Secondary & $54(36.0)$ \\
\hline Above secondary & $46(30.6)$ & Above secondary & $20(13.3)$ \\
\hline \multicolumn{2}{|l|}{ Fathers' occupation } & \multicolumn{2}{|l|}{$\begin{array}{l}\text { Mothers' } \\
\text { occupation }\end{array}$} \\
\hline Service & 73 (48.7) & Service & $08(05.3)$ \\
\hline Business & 26 (17.3) & Housewife & $142(94.7)$ \\
\hline Farmer & $37(24.7)$ & Water supply & \\
\hline \multirow[t]{2}{*}{ Others } & \multirow[t]{2}{*}{$14(09.3)$} & Tube well & $131(87.3)$ \\
\hline & & Tap water & 19 (12.7) \\
\hline
\end{tabular}

Table III shows, patients who developed first attack of diarrhea by 6 months of age were 6 (10.2\%) from exclusively breast fed, 41 (69.5\%) from breast fed plus formula fed, and 12 (20.3\%) from exclusively formula fed group. Patients who developed diarrhea by 7-12 months of age, 44 (69.8\%), 17 (27.0\%) and 2 (3.2\%) respectively developed in exclusively breast fed, breast fed plus formula fed and exclusively formula fed group. Twenty eight patients developed diarrhea by 13-24 months of age; among them 27 (96.4\%), and 1 (3.6\%) were from exclusively breast fed, and breast fed plus formula fed group respectively (p value .000).

Table IV shows, children of illiterate mother had more frequent diarrheal attack (63.6\%) than literate mother but educational level did not influenced consistently on occurrence and frequency of diarrheal attack on the study population (p value .02).

Table V shows, there is no significant influence of source of water on diarrheal attack and frequency in different group of patient (p value .407).

Table VI shows, residence of patients did not influenced on frequency of diarrheal attack ( $p$ value .084). 


\section{Table-II}

\section{Feeding information, number of diarrheal attack and age of first occurrence}

\begin{tabular}{lc} 
Parameters & No. (\%) \\
\hline Feeding & $77(51.3)$ \\
Exclusively breast fed & $59(39.3)$ \\
Breast fed plus formula fed & $14(09.4)$ \\
Exclusively formula fed & $50(33.3)$ \\
Pre-lacteal fed & \\
First occurrence of diarrhea & $59(39.3)$ \\
1-6 month & $63(42.0)$ \\
7-12 month & $28(18.7)$ \\
13-24 month & \\
Number of diarrheal attack & $84(56.0)$ \\
1st attack & $58(38.7)$ \\
2nd attack & $2(1.3)$ \\
3rd attack & $6(4.0)$ \\
4th attack or more & \\
Formula feeding utensils & $55(76.4)$ \\
Bottle & $17(23.6)$ \\
Cup and spoon &
\end{tabular}

\section{Table-III}

Type of feeding versus age of first occurrence of diarrhea

\begin{tabular}{lcccc} 
& \multicolumn{2}{c}{ Type of feeding versus age of first occurrence of diarrhea } \\
Age of first diarrhea & \multicolumn{3}{c}{ Feeding } & Total \\
\cline { 2 - 4 } & $\begin{array}{c}\text { Exclusive breast } \\
\text { feeding (\%) }\end{array}$ & $\begin{array}{c}\text { Breast } \\
\text { feeding+Formula } \\
\text { feeding (\%) }\end{array}$ & $\begin{array}{c}\text { Exclusively } \\
\text { formula } \\
\text { feeding (\%) }\end{array}$ \\
\hline o-6 month & $06(10.2 \%)$ & $41(69.5 \%)$ & $12(20.3 \%)$ & 59 \\
7-12 month & $44(69.8 \%)$ & $17(27.0 \%)$ & $02(3.2 \%)$ & 63 \\
13-24 month & $27(96.4 \%)$ & $01(3.6 \%)$ & - & 28 \\
Total & 77 & 59 & 14 & 150 \\
\hline
\end{tabular}

Table-IV

\begin{tabular}{lccc}
\multicolumn{4}{c}{ Relation between Mothers' education and number of diarrheal attack } \\
Mothers' education & Single attack (\%) & Two or more attack (\%) & Total \\
\hline Illiterate & $08(36.4 \%)$ & $14(63.6 \%)$ & 22 \\
Primary & $31(57.4 \%)$ & $23(42.6 \%)$ & 54 \\
Secondary & $33(61.1 \%)$ & $21(38.9 \%)$ & 54 \\
Above secondary & $12(60.0 \%)$ & $08(40.0 \%)$ & 20 \\
\hline Total & $84(56.0 \%)$ & $66(44.0 \%)$ & 150 \\
\hline
\end{tabular}


Table-V

\begin{tabular}{lccc} 
& \multicolumn{2}{c}{ Relation between water supply and number of diarrheal attack } \\
Water supply & single attack (\%) & Two or more attack (\%) & Total \\
\hline Tube well & $73(55.7 \%)$ & $58(44.3 \%)$ & 131 \\
Tap water & $11(57.9 \%)$ & $08(42.1 \%)$ & 19 \\
\hline Total & $84(56.0 \%)$ & $66(44.0 \%)$ & 150 \\
\hline
\end{tabular}

Table-VI

\begin{tabular}{lccc}
\multicolumn{4}{c}{ Relation between residence and number of diarrheal attack } \\
Residence & Single attack (\%) & Two or more attack (\%) & Total \\
\hline Urban & $39(60.0 \%)$ & $26(40.0 \%)$ & 65 \\
Urban slum & $03(50.0 \%)$ & $03(50.0 \%)$ & 06 \\
Rural & $42(53.2 \%)$ & $37(46.8 \%)$ & 79 \\
\hline Total & $84(56.0 \%)$ & $66(44.0 \%)$ & 150 \\
\hline
\end{tabular}

\section{Discussion:}

Breast milk is the ideal food for an infant's first six months of life. Colostrum and breast milk contains an abundant amount of $\operatorname{IgA}_{2}$ and other antibodies that can help the baby to resist infections ${ }^{3}$. Breastfeeding has many health benefits for both the mothers and infants. In addition to providing ideal nourishment, breastfeeding provides infants with protection from many infections, including diarrheal diseases. Breastfeeding can also reduce the severity, duration, and negative nutritional consequences of diarrhea ${ }^{4}$. On the other hand, use of formulas including infant formula is associated with increased health risks such as acute gastroenteritis, otitis media, severe lower respiratory tract infections, atopic dermatitis, asthma and obesity ${ }^{5}$. The infant's intestine is not properly ready to digest non-human milk and this may often result in diarrhea, intestinal bleeding and malnutrition ${ }^{6}$. In our study, we found more than half (51.3\%) of the study population were exclusively breastfed and single attack of diarrhea occurred in all children (as per inclusion criteria). But frequent (two or more) attack of diarrhea occurred in non-exclusive breast fed children; in breast fed plus formula fed children 35 (59.3\%), exclusively formula fed 10 (71.4\%) and exclusively breast fed 21 (27.3\%). Abdulbari Bener et al. ${ }^{7}$ study on exclusive breast feeding and prevention of diarrheal diseases showed more than half of the infants (59.3\%) were exclusively breastfed; the risk for presenting diarrhea was higher in formula fed (48.7\%) and partially breastfed children (37.3\%) when compared to exclusively breast fed (32.5\%). Black RE et al. ${ }^{8}$ study on Maternal and child under nutrition showed, the relative risk for prevalence of diarrhea was more in predominant and partial breastfeeding (1.26 and 3.04 respectively) as compared to exclusive breastfeeding.

World Health Organization (WHO) recommends exclusive breast feeding for first six months of life and continuation of breast feeding for two years or beyond ${ }^{9,10}$. We found 59 patients developed first attack of diarrhea by 6 months of age, of whom most children were from non-exclusively breast fed group; there were breast fed plus formula fed children 41 (69.5\%), exclusively formula fed 12 (20.3\%) and exclusively breast fed only 6 (10.2\%). This finding reflects exclusive breastfeeding has influence on prevention of early occurrence of diarrhea. On the other hand, patients who developed first attack of diarrhea by 7-12 months and 13-24 months of age mostly were from exclusively breast fed group (69.8\%, and 96.4\%) respectively) indicating later occurrence of diarrhea in exclusively breast fed children than non- exclusively breast fed one. Our finding correctly supports current WHO recommendation on breast feeding. Laura M Lamberti et al. ${ }^{11}$ study on breastfeeding and the risk for diarrhea morbidity and mortality showed excess risk of diarrhea 
in non-exclusively breast fed 0-5 months aged infants; relative risk of diarrheal incidence was $1.26,1.68$, and 2.65 in predominant, partial, and non-breastfed group children respectively. Similarly, the estimated relative risk of incident diarrhea was elevated when comparing non-breastfed to breastfed 6-11 months aged infants.

We have observed the relationship of diarrheal incidence with other demographic parameters also. But residence, water supply, sanitation and parent's educational level had no significant influence on incidence and frequency of diarrhea.

\section{Conclusion:}

Breast feeding reduces incidence of diarrhea, prevents frequent attack and early occurrence of diarrhea in under two children. Residence, water supply, sanitation and parent's educational status may not have significant influence on incidence of diarrhea.

\section{References:}

1. World Health Assembly: Global strategy on infant and young child feeding: 2002; 55 (15); 10.

2. Kramer MS,Chalmers B, Hodnett ED, Sevkovskaya Z, Dzikovich I,Shapiro S, Collet JP; Promotion of Breastfeeding Intervention Trial (PROBIT): A randomized trial in the Republic of Belarus. J Am Med Asso 2001, 285(4): 413-420

3. Islam SK, Ahmed L, Khan NI, Haque S, Begum A, Yunus AB. Immune components (IgA, IgM, IgG, immune cells) of colostrums of Bangladeshi mothers. Pediatric International; 2006; 48; 543-8.

4. Positive Alternative Therapies in Healthcare (PATH); Path Factsheet:Breastfeeding and diarrhea: 2008; 1-2.

5. Stanley Ip, Mei Chung, Gowri Raman, Priscilla Chew, Nombulelo Magula, Deirdre DeVine, Breast feeding and Maternal and Infant Health Outcomes in Developed Countries. AHRQ publication; 2007;153;1-415

6. Jiang, Jeter, Nelson, and Ziegler; "Intestinal Blood Loss During Cow Milk Feeding in Older Infants”. Arch Pediatr Adolesc Med. 2011; 154 (7): 673-678.

7. Abdulbari Bener, Mohammad S. Ehlayel, Hatim M. Abdulrahman; Exclusive breast feeding and prevention of diarrheal diseases. A study in Qatar; Rev. Bras. Saude Mater. Infant. 2011; 11 (1): 83-87.

8. Black RE, Allen LH, Bhutta ZA, Caulfield LE, de Onis M, Ezzati M; for the Maternal and Child Undernutrition Study Group. Maternal and child undernutrition: global and regional exposures and health consequences. Lancet 2008; 371: 243-260.

9. Siddarth, Ramji. Impact of infant and young children feeding and caring practices. On nutrition status and health. Indian J Med 2007;91:624-26

10. Ghosh R, Mascil, Taylor CG, Rosetta L; Longitudinal study of the frequency and duration of breast feeding in rural Bangladeshi women. Am J Hum Biol, 2006;15;630-35.

11. Laura M Lamberti, Christa L Fischer Walker, Adi Noiman, CesarVictora, and Robert E Black; Breast feeding and the risk for diarrhea morbidity and mortality; BMC Public Health, 2011; 11; 13-15. 